\title{
Specifics of system of external influences on the life cycle of a construction object
}

\author{
Aleksander Aleksanin ${ }^{1, *}$, and Sergey Sborshikov ${ }^{1}$ \\ ${ }^{1}$ Moscow State University of Civil Engineering, Moscow, Russian Federation
}

\begin{abstract}
There is a very important issue today which includes the harmonious and effective development of the system 'man -environment'. Construction is a branch of material production, which has a significant negative impact on the world around us. It is necessary to plan and operate processes of construction at all stages of the life cycle of a building without exception, to prevent of ecological threats. The article describes the concept of 'life cycle' as applied to various fields of knowledge, analyzes existing in the scientific literature division of the life cycle of buildings in the periods, proposes own approach to the division of periods of the life cycle on the basis of resource-saving. The article proposes the creation of a unified organizational system for the effective management of all periods with the constituent phases and formulates the main external influences on the building life cycle.
\end{abstract}

The present stage of development of the construction industry is characterised by close inter-relationship with the natural environment. The harmonious development of the construction and the natural environment is the key to sustainable development of the system 'man - environment'. To date, there is the task of organization all the processes accompanying the creation of the construction object in a single control system, starting with the stages of initiation and pre-investment and ending with decommissioning or its liquidation. One of the main criteria for the operation of this system, in the first place, should be the focus on the balanced development of the environment. The decision of this task is based on the need to develop a set of measures to streamline and improve the existing mechanisms of formation and functioning of the processes in the context of the life cycle of a construction object. The process of creating a construction object can be divided into sub-processes, the interaction of regulation which will contribute to the harmonious coexistence of the construction object and the surrounding world.

Let's consider stages of life cycle of the object, most often meeting in modern scientific works. The concept of 'life cycle' is widely used in many fields of knowledge, such as in biology, this term means the consequent shift of all generations, characteristic for this type of living organisms. In economics, there is the concept of 'life cycle of the organization' - a set of developmental stages which runs the firm during the period of its existence.

For our research the most interesting definition is 'the life cycle of a building '. The life cycle of a building is a period during which carried out engineering survey, design,

*Corresponding author: aleks08007@mail.ru 
construction (including conservation), operation (including current repairs), reconstruction, major repairs, demolition of a building or structure.

There is a lot of works of foreign authors, which devoted to scientific researches of the life cycles [1-5], many of them are directly related to energy efficiency and resource saving [6-9]. In the scientific and technical literature distinguish the following periods of a building's life cycle [10]:

1. The 1-st period is the process of developing a feasibility study for construction of the building;

2. The 2-d period is the process of developing of construction and design decisions;

3. The 3-d period is process of building, together with the development of technology, organization and technological regulations of work;

4. The 4-th period is the process of pre-service development;

5. The 5-th period is directly operation of buildings and work aimed at ensuring payback of funds invested in their creation;

6. The 6-th period is processes of manufacture scheduled preventive and major repairs to maintain in a good technical condition of constructive elements and engineering systems of the building;

7. The 7-th period is the stage, both physical and moral deterioration of the building, when necessary to carry out works on modernization, reconstruction or demolition;

8. The 8-th period is reconstruction, restoring physical, mechanical and operational characteristics of the buildings. This period include also 1-st and 2-d periods of feasibility study and development of technical documentation.

There are scientific papers in which the authors identify some types of life cycle of object of the real estate: economic, legal and physical. From an economic point of view there are three periods: construction (step up investments and investment stage); exploitation to the point where the object is fully pay for themselves (the entrepreneurial stage of the project); operation in the subsequent growth of the results on investment (innovation, facility closing). From a legal point of view, allocate periods of registration of ownership; possession, use, disposal; change of ownership; registration of liquidation [11].

It is necessary to distinguish the concept of 'life cycle of a construction object' and 'the life cycle of a construction project'. The authors offer the following life cycle stages of construction project: pre-investment stage, stage design, stage management, stage of implementation [12]. The life cycle of a universal project can be represented by the following phases:

- Definition of goals and objectives;

- Development concept;

- Design;

- Examination;

- Decision on the implementation of the project;

- Implementation of the project;

- Monitor the implementation;

- Evaluation and analysis of results;

- Completion of the project.

Within the framework of scientific research suggests to integrate described above periods of the life cycle of the construction object and to allocate only three major:

- Creation of an object;

- Exploitation of an object;

- Limination of an object.

The period 'creation of an object' combines phase feasibility study, design and construction. This stage also includes the phase of production of building materials, as it accumulates a huge potential resource in the implementation of the next phase. 
So, each of the periods of the life cycle of the construction object includes certain phases.

The period of 'Creation of an object' contains a phases:

- Production of construction materials;

- Predesign development and researches;

- Design works;

- Construction and installation works.

The period of 'Exploitation of an object' contains a phases:

- Works to improve the energy efficiency of the facility;

- Maintenance works on the facility;

- Maintenance repairs;

- Capital repairs.

In this period a special place is occupied by improving energy efficiency, because during the operation of the building development of scientific and technological progress does not stop, and develops new energy-saving systems.

The period of 'Elimination of an object' contains a phases:

- The dismantling and demolition of buildings;

- Works on the disposal of construction and demolition waste;

- Works on the processing of construction and demolition waste.

For the effective management of all periods with the constituent phases, it is proposed to create a unified organizational system. The system has its own life cycle, comprising the steps of the process, covering a variety of state of the system, starting from the moment of the need for such a system, and ending with its complete decommissioning [13].

This organizational system is closely related to the impacts of external environment in the form of federal, regional or municipal authorities, the population, the level of development of scientific and technical progress, etc. The main external influence is the administrative and legal impact, economic impact, social impact, and the impact of science and technology. Scheme of impacts in terms of construction object lifecycle is shown in Figure 1.

Administrative and legal influence is due to the publication of new administrative regulations, standards, regulations, etc. The economic influence is a powerful regulatory tool, the essence of which is the availability of funds for works on a particular period. The social impact is the attitude of the society to the life cycle of the building, for example, the protests at a hearing on new construction projects in areas with unique natural landscapes, the lack of demand for products, realized within the functioning of buildings (space rental, attendance at trade and entertainment buildings, etc.). The impact of scientific and technological progress is the creation of new building materials, the development of modern technical, technological and organizational methods of the construction of buildings and structures.

The indispensable condition to demolish buildings and structures it is almost total recycling of construction waste and their subsequent use in the construction of new facilities, which reduces the impact on the environment in the extraction of raw materials $[14 ; 15]$. Thus, the life cycle of a single object of construction is obtained related to the life cycle of other objects. The high level of development of the market of construction and demolition waste contributes to the effective provision of recyclable material of new objects [16; 17]. The basis of sustainable development of natural and man-made environment is a balanced functioning of the system life cycle of construction projects based on resource conservation policy. 


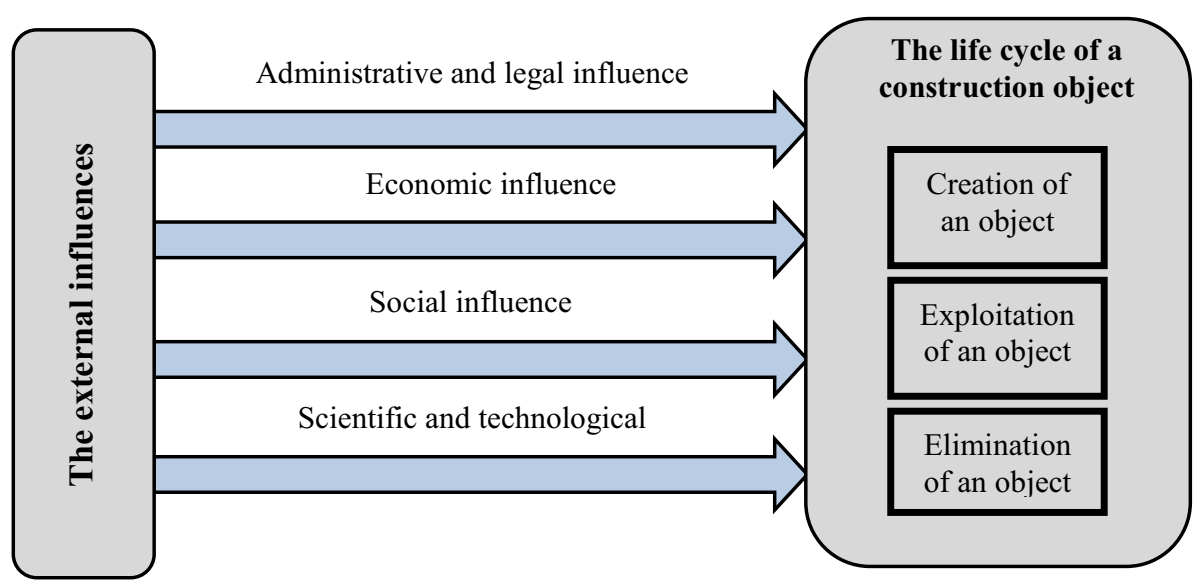

Fig.1. Scheme of the system impacts in the context of construction project life cycle.

It is necessary to take into account the fact that continuous improvement of production of construction materials and the emergence of new innovative technologies in the creation of the organizational life cycle management system of buildings. If we analyze the building, built in the XX century, it is possible to get an idea about the changes of the basic materials of building structures. For example, the buildings of the first half of the 20th century were wooden, clay and stone; in the second half of the 20th century building built of brick, block, panel; in the late twentieth and early twenty-first century is monolithic. The architects proposed many variants of the buildings of the future today. It is believed that the main trends of the construction will be ecology, mobility, self-reliance and full automation of all systems running artificial intelligence. Already practiced production of bricks from waste rice husk, the use of smart glass, which are capable of generating electricity, the introduction of a shell building facades, regulating indoor climate [18-20]. Perhaps, in the not too distant future it will be impractical to construct buildings from recycled designs objects built hundreds of years ago.

\section{References}

1. A.F.A. Rashida, S. Yusoffb. Renew, Sustainable Energy Rev. 45, 244 (2015)

2. C.K. Chau, T.M. Leung, W.Y., Ng. Appl. Energy 143, 395 (2015)

3. I. Kovacic, V. Zoller, Energy 92, 409 (2015)

4. S. Butera, T.H. Christensen, T.F. Astrup, Waste Management 44, 196 (2015)

5. J. Honga, G. Q. Shena, C. Maob, Z. Lia, K. Lib, Journal of Cleaner Production 112, $2198(2016)$

6. V. Motuzienèa, A. Rogožaa, V. Lapinskienėa, T. Vilutienèb, Journal of Cleaner Production 112, 532 (2016)

7. M. S. Tokarik, R. C. Richman, Energy Build 118, 160 (2016)

8. S. Proiettia, P. Sdringolaa, U. Desideria, F. Zepparellia, F. Masciarellib, F. Castellania, Energy Build 64, 463 (2013)

9. L. F. Cabezaa, L. Rincóna, V. Vilariñob, G. Péreza, A. Castella. Renew. Sustainable Energy Rev 29, 394 (2014)

10. A.A. Afanasev, E.P. Matveev. Reconstruction of residential buildings (Moscow, 2008)

11. P.V. Fedyaeva Organizational and technological support for improving energy efficiency in the housing sector of the Russian Federation (Cand.Tech.Sci., 2015) 
12. V.V. Kuschenko, Development. The modern concept for the development of Real property (Moscow, 2005)

13. B.S. Blanchard, W.J. Fabrycky, Systems engineering and analysis (Prentice Hall, 2006)

14. A.V. Aleksanin, S.B. Sborshikov. Industrial and Civil Engineering 11, 84 (2014)

15. A.V. Aleksanin, Scientific and Technical Volga region Bulletin 5, 94 (2014)

16. A.V. Aleksanin, Industrial and Civil Engineering 10, 79 (2014)

17. A.V. Aleksanin, S.B. Sborshikov,Vestnik MGSU 6, 229 (2013)

18. C. Ionescu, T. Baracu, G-E. Vlad, H. Necula, A. Badea. Renew, Sustainable Energy Rev. 49, 243 (2015)

19. R. Volk, J. Stengel, F. Schultmann, Automation in Construction 38, 109 (2014)

20. M. L. Rosenzweig, Israel Journal of Ecology \& Evolution 62, 7 (2016) 